\title{
Использование кластерного анализа химического состава растений в хемосистематике
}

\section{Usage of cluster analysis of chemically compounds of plants for taxonomy}

\author{
Круглов Д. С. \\ Kruglov D. S. \\ Новосибирский государственный медицинский университет, г. Новосибирск, Россия. E-mail: kruglov_ds@mail.ru
}

Novosibirsk State Medical University, Novosibirsk, Russia

\begin{abstract}
Peфepam. В настоящей работе был проведен кластерный анализ микроэлементного состава растений родов Pulmonaria, Vaccinium, Oxycoccum и компонентного спектра эфирного масла, полученного из растений рода Filipendula. Были построены дендрограммы распределения исследуемых растений по кластерам по их микроэлементному спектру и компонентному составу эфирных масел. В результате было установлено, что и микроэлементный состав растения так же, как и компонентный состав эфирного масла являются видоспецифичными и могут использоваться в хемосистематике. Распределение растений по кластерам коррелирует с систематическим положением исследуемых видов по общепринятым в систематике морфологическим признакам. Таким образом, применение кластерного анализа позволяет реализовать технологию «Fingerprinting» и использовать микроэлементный спектр растения так же, как и компонентный спектр продуцируемого эфирного масла в качестве спектров-маркеров в задачах систематики.
\end{abstract}

Ключевые слова. Кластерный анализ, микроэлементный состав, хемосистематика, эфирное масло, Pulmonaria, Vaccinium, Filipendula.

Summary. The cluster analysis of trace element structure of plants of Pulmonaria, Vaccinium and Oxycoccum genuses and essential oil composition taken from species of Filipendula genus was done in presented work. Hierarchical trees of distribution of the investigated plants into clusters were constructed by using of their trace element spectra and component composition of essential oils. As a result, it was established that both trace element structure of plants and component composition of essential oil are species-specific elements and they can be used in a chemotaxonomy. Distribution of plants on clusters correlates with the taxonomy position of investigated species, which was assayed by using of the common morphological features. Thus, application of the cluster analysis allows to make "Fingerprinting" technology and to use trace element spectra of plant as well as component spectra of produced essential oil as spectra-markers for taxonomy tasks.

Key words. Chemotaxonomy, cluster analysis, trace element composition, essential oil, Pulmonaria, Vaccinium, Filipendula.

Использование алкалоидов, изопреноидов, фенольных соединений и других низкомолекулярных природных соединений в качестве таксономических признаков широко используются в хемосистематике. При этом таксономическими маркерами выступают доминантные компоненты, и они весьма успешно используются для решения задач хемотаксономии и филогении (Высочина, 2004). В частности, для эфирномасличных растений весьма информативным является компонентный состав эфирного масла (представленный чаще всего соединениями изопреноидной природы). Вместе с тем, наряду с доминантными компонентами, в спектре эфирного масла присутствуют минорные компоненты, которые и формируют вместе с доминанитым соединением видовой спектр и в конечном итоге, собственно, видоспецифичность продуцируемого растениями эфирного масла. Очевидно, что использование спектра (как совокупности достаточно большого числа индивидуальных соединений) компонентного состава для хемосистематики возможно по аналогичной для генома технологии «Fingerprinting» (Weising et al., 2005). 
В то же время для биосинтеза различных метаболитов растительному организму нужен вполне определенный набор микроэлементов, служащих в качестве простетических компонентов регуляторов биохимических процессов такого синтеза. Ранее был изучен микроэлементный состав более 55 растений из 34 родов семейства Boraginaceae, собранных на территории Африки и Евразии и произрастающих на почвах с заведомо различными характеристиками, и было установлено, что микроэлементынй статус (или спектр) растения зависит от его генотипа (Круглов, Овчинникова, 2012). Таким образом, можно предполагать, что и микроэлементный спектр растения может использоваться в хемосистематики с применением для его анализа все той же технологии «Fingerprinting».

Важной задачей для внедрения технологии «Fingerprinting» является формализация задачи необходимая для воспроизводимой и счетной реализации данного метода. Для работы с такими многофакторными данными весьма эффективно применение одного из методов «распознавания образов» метода кластерного анализа. При проведении анализа вводится понятие абстрактного многомерного пространства. Исследуемый объект в таком пространстве (в данном случае исследуемый спектр) характеризуется вполне определенным и только ему присущим положением в этом пространстве. Группа схожих между собой объектов образуют в таком пространстве некий кластер. С помощью метода древовидной кластеризации формируются кластеры несходства, которые значимо отличаются друг от друга по критерию относительного расстояния между ними и строится «иерархическое дерево». В качестве меры расстояния между различными кластерами обычно принимается геометрическое расстояние в многомерном пространстве (Евклидово расстояние). При этом в качестве меры минимального расстояния между значимо различными кластерами было предложено принять изменчивость содержания микроэлементов по заросли. Применительно к растительным объектам была показана (Круглов, $2018)$ возможность такого подхода к реализации технологии «Fingerprinting» при анализе многокомпонентных спектров.

В качестве объектов исследования микроэлементного состава были приняты:

a) надземные части наиболее распространенных растений рода Pulmonaria - P. officinalis L., P. obscura Dumort, P. mollis Wulf. ex Hornem., P. mollis f. albiflora, P. rubra Schott, P. angustifolia L., coбранные в наиболее типичных для вида местах его ареала в фазу цветения. Сырье $P$. mollis f. albiflora было собрано на экспозиционном участке Центрального сибирского ботанического сада;

б) листья растений семейства Ericaceae: род Vaccinium - V. vitis-ideae L., V. vitis-ideae subsp. minus, V. hirtum Thunb, V. uliginosum L., V. myrtillus L., V. ovalifolium Smith., V. praestans Lamb., V. arctostaphylos L. и род Oxycoccus - O. microcarpus Turcz., O. palustris Pers., собранные в фазу плодоношения.

Собранное сырье высушивалось и измельчалось. Из измельченного сырья отбирались образцы для анализа, которые подвергались разложению смесью кислот с использованием систем микроволновой пробоподготовки. Содержание микроэлементов определялось методом масс-спектроскопии с индуктивно связанной плазмой на приборе «ELAN-DRC» (Круглов, 2010).

В результате было установлено содержание 59 элементов ( $\mathrm{Li}, \mathrm{Be}, \mathrm{B}, \mathrm{Na}, \mathrm{Mg}, \mathrm{P}, \mathrm{K}, \mathrm{Ca}, \mathrm{Ti}, \mathrm{V}, \mathrm{Cr}, \mathrm{Mn}$, $\mathrm{Fe}, \mathrm{Co}, \mathrm{Ni}, \mathrm{Cu}, \mathrm{Zn}, \mathrm{Ga}, \mathrm{Ge}, \mathrm{As}, \mathrm{Se}, \mathrm{Br}, \mathrm{Rb}, \mathrm{Sr}, \mathrm{Y}, \mathrm{Zr}, \mathrm{Nb}, \mathrm{Mo}, \mathrm{Ag}, \mathrm{Cd}, \mathrm{Sn}, \mathrm{Sb}, \mathrm{I}, \mathrm{Cs}, \mathrm{Ba}, \mathrm{La}, \mathrm{Ce}, \mathrm{Pr}, \mathrm{Nd}, \mathrm{Sm}, \mathrm{Eu}, \mathrm{Gd}, \mathrm{Tb}, \mathrm{Dy}$, Ho,Er,Tm,Yb,Lu,Hf,Ta,W,Au,Hg,Tl,Pb,Bi,Th,U).

В качестве объектов исследования компонентов эфирного масла были приняты соцветия растений рода Filipendula: F. angustiloba Maxim., F. camtschatica Maxim., F. denudata Fritsch., F. glaberrima Nakai, F. intermedia Juz., F. palmata Maxim., F. picbaueri Smejkal., F. ulmaria Maxim., F. vulgaris Moench., собранные в фазу цветения.

С целью получения наиболее адекватной информации о компонентном составе эфирных масел в качестве метода экстракции летучих компонентов был выбран метод твердофазной экстракции на проволоке-адсорбенте (Круглов и др., 2019). Газовую хроматографию, совмещенную с масс - спектрометрическим анализом, проводили с использованием хромато-масс- спектрометра 6890N (Agilent Technologies). Для идентификации использовались библиотеки масс- спектров, а также проводилось сравнение времени удерживания с таковыми для стандартных образцов. 
В результате было установлено, что компонентный профиль летучих компонентов, образующих эфирное масло цветков видов Filipendula, представлен 19-ю соединениями фенольной и изопреноидной природы при доминировании фенолов - метилсалицилата и салицилового альдегида, на долю которых приходится более 50 \% массы эфирного масла.

Кластерный анализ микроэлементных и эфирномасличных спектров проводили с использованием пакета прикладных программ "Statistica - 8", причем кластеры считались обоснованно различными, если относительное расстояние между ними в $\mathrm{N}$ - мерном пространстве превышало $20 \%$ - т. е. превышало изменчивость содержания микроэлементов по заросли, определенную ранее в размере $15 \%$.

Построенные в результате кластерного анализа дендрограммы приведены на рисунках 1-3.

Анализ дендрограммы, построенной по микроэлементному спектру растений рода Pulmonaria (рис. 1.), показывает, что исследуемые растения разделяются на 4 кластера, коррелирующих с таковым разделением их по известным морфологическим признакам. Вполне логично и объединение двух форм P. mollis в один кластер - очевидно, что разница между ними незначительна “a priori”.

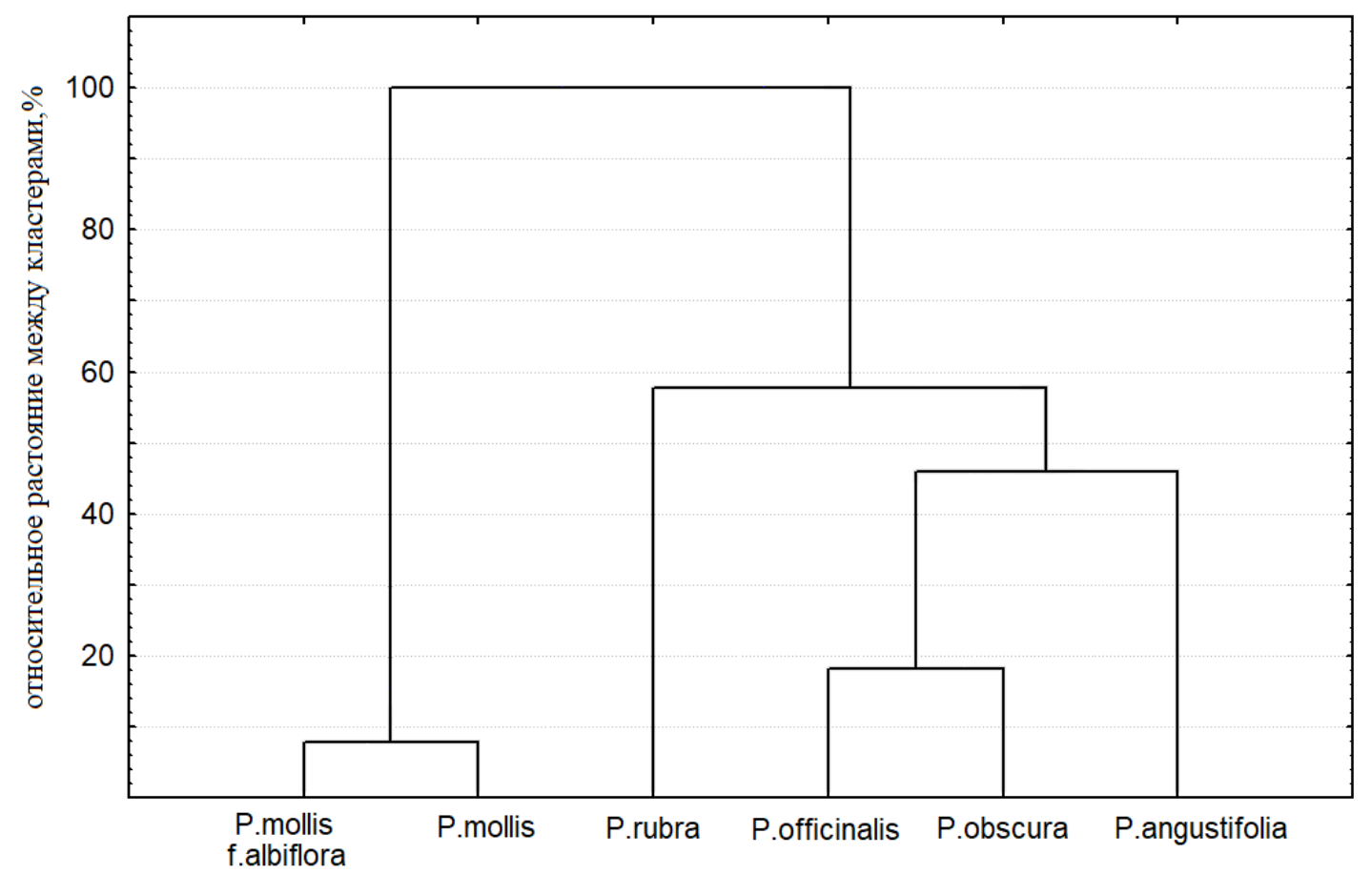

Рис. 1. Дендрограмма видов рода Pulmonaria по микроэлементному спектру.

В свою очередь виды родов Vaccinium и Oxycoccus распределились по кластерам (рис. 2.) таким образом:

1-ый - V.hirtum;

2-ой - V. uliginosum, V. myrtillus, V. ovalifolium, V. praestans;

3-ий - V. arctostaphylos;

4-ый - O.microcarpus, O.palustris.

Полученное распределение практически совпадает с систематическим положением рассматриваемых родов и видов (Малышев, 1997), а для рода Vaccinium коррелирует с известным систематическим разделением его на для секции Cyanococcus, Vaccinium и Vitis-ideae, за исключением $V$. arctostaphylos, который отнесен к секции Vitis-ideae. Следует заметить, что по ряду морфологических признаков V. arctostaphylos может быть отнесена и к секции Vaccinium (Зернов, 2006).

Анализ дендрограммы, построенной по компонентному спектру эфирных масел (рис. 3.), показывает, что исследуемые виды рода Filipendula объединены в три кластера: 
1-ый - F. camtschatica, F.glaberrima, F. palmata, F.angustiloba u F.intermedia;

2-ой - F. ulmaria, F. denudata, F. picbaueri;

3-ий - F.vulgaris.

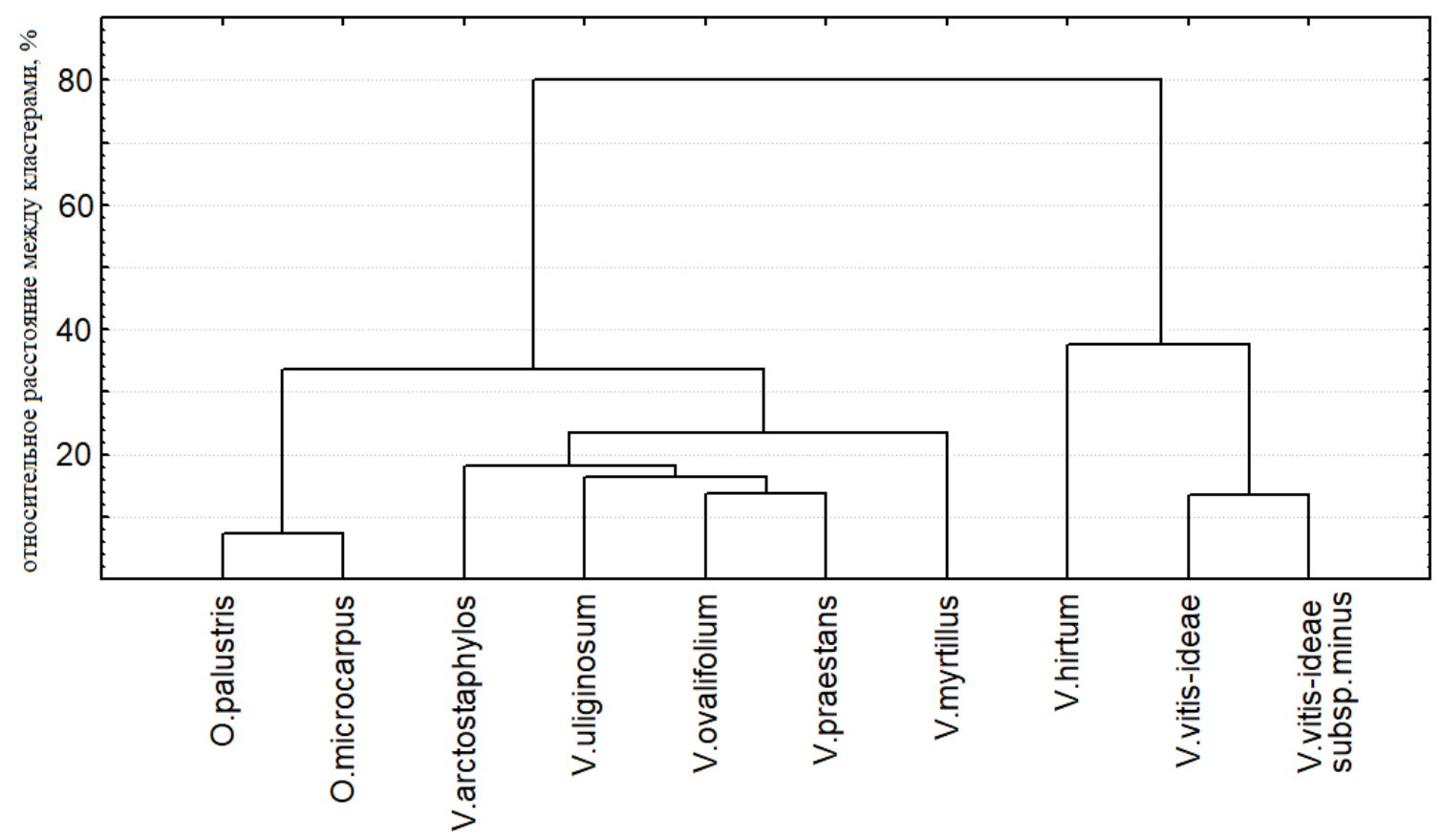

Рис. 2. Дендрограмма видов родов Vaccinium и Oxycoccus по микроэлементному спектру.

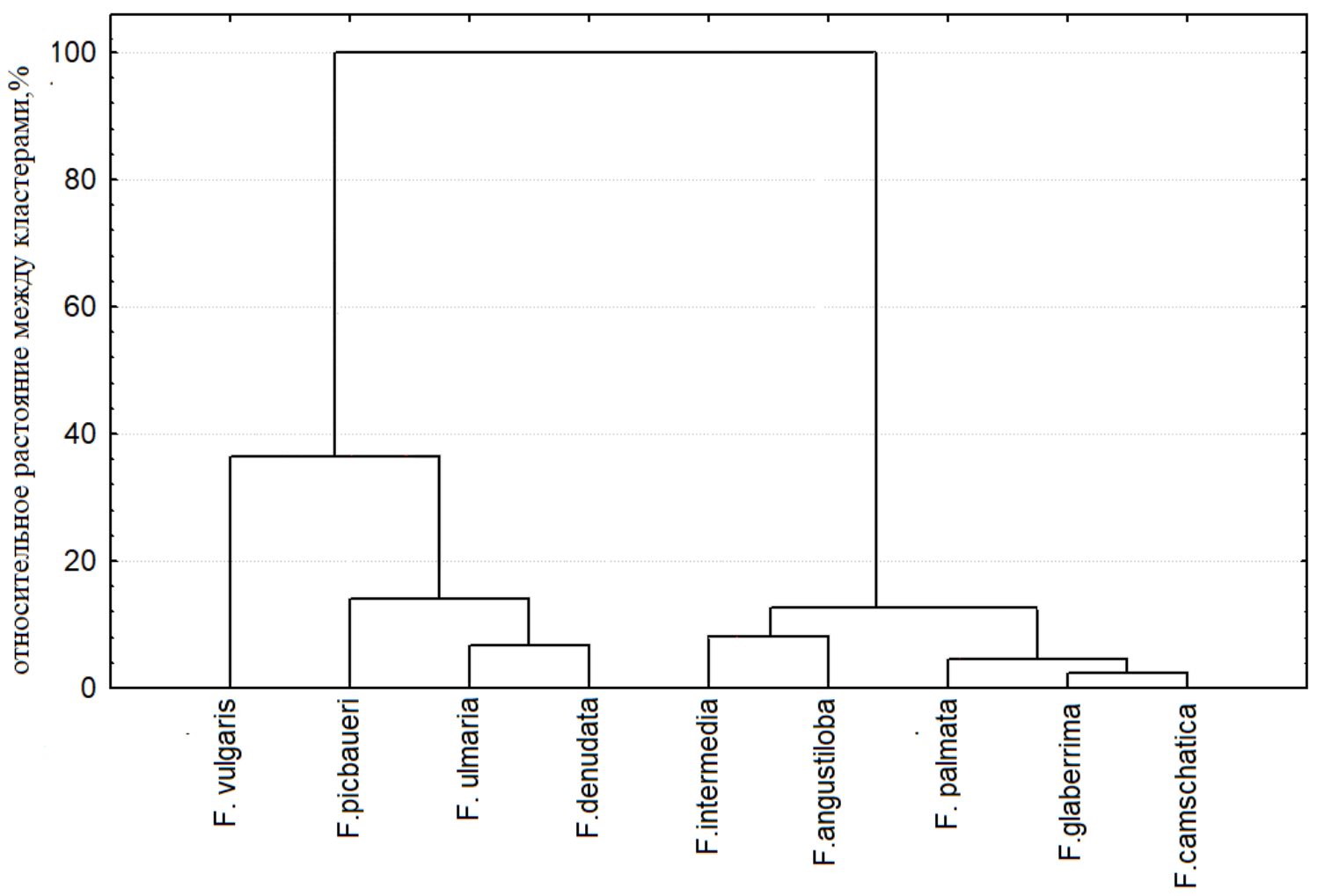

Рис. 3. Дендрограмма видов рода Filipendula по компонентному спектру эфирного масла. 
Полученное распределение полностью коррелирует с систематическим положением исследуемых видов (Камелин, 2001) - они в этом же объеме распределены по подродам - Aceraria, Ulmaria и Filipendula и, более того, внутри группы 1 наблюдается четкое деление видов согласно систематическому положению: подгруппа 1 (F. camtschatica, F.glaberrima, F. palmata) - секция Schalameya, подгруппа 2 (F.angustiloba u F.intermedia) - секция Albicoma.

Таким образом, применение кластерного анализа позволяет реализовать технологию «Fingerprinting» и использовать микроэлементный спектр растения так же, как и компонентный спектр продуцируемого эфирного масла в качестве спектров-маркеров в задачах систематики.

\section{ЛИТЕРАТУРА}

Высочина $\boldsymbol{\Gamma}$. И. Фенольные соединения в систематике и филогении семейства гречишных. - Новосибирск: Наука, 2004. - 204 c.

Зернов А. С. Флора Северо-Западного Кавказа. - М.; Товарищество научных изданий КМК, 2006. - 664 с.

Камелин Р. В. Род Filipendula Mill. // Флора Восточной Европы. - СПб.: Мир и семья; изд-во СПХФА, 2001. - T. X. - C. 314-317.

Круглов Д. С. Индивидуальная изменчивость элементного состава надземной части Pulmonaria mollis Horn. // Химия растительного сырья, 2010. - №1. - С. 131-136.

Круглов Д. С. Прогностическая применимость микроэлементного профиля растений для задач систематики // Ботаника в современном мире: Труды РБО. Т. 1: Систематика высших растений. Флористика и география растений. Охрана растительного мира. Палеоботаника. Ботаническое образование. - Махачкала: АЛЕФ, 2018. - С. $58-60$.

Круглов Д. С., Овчинникова С. В. Элементный состав растений семейства Boraginaceae // Растительный мир Азиатской России, 2012. - № 1(9). - С. 77-95.

Круглов Д. С., Круглова М. Ю., Оленников Д. Н. Взаимосвязь микроэлементного статуса и компонентного состава эфирного масла растений рода л абазник// Химия растительного сырья, 2019. - №1. - С. $201-207$.

Малышев Л. И. Семейство Ericaceae - Вересковые//Флора Сибири. - Новосибирск: Наука, 1997. - Т. 11. - С. 14-29.

Weising K., Nybom Y., Wolff K., Kahl G. DNA Fingerprinting in Plants: Principles, Methods, and Applications: CRC PressTaylor et Francis Group. - New York, 2005. - 444 p. 